\title{
Dual Training System Integration for Caregiver School in Cebu City
}

\author{
Leovigilda L. Bithay \\ CTU-Main Campus, Cebu City, Philippines \\ Email: Leovil75@gmail.com
}

How to cite this paper: Bithay, L.L. (2020) Dual Training System Integration for Caregiver School in Cebu City. Open Access Library Journal, 7: e6002. https://doi.org/10.4236/oalib.1106002

Received: January 2, 2020

Accepted: January 17, 2020

Published: January 20, 2020

Copyright $\odot 2020$ by author(s) and Open Access Library Inc.

This work is licensed under the Creative Commons Attribution International License (CC BY 4.0).

http://creativecommons.org/licenses/by/4.0/

\begin{abstract}
This research assessed the integration of the Technical Education Skills Development Authority (TESDA) Dual Training System of the identified Caregiver Schools in Cebu City, Philippines. This is anchored on Christian Wolff's theory that the mind has mental powers or faculties such as memory, reason, judgment, attention, will and observation; these functions have separate entity that can be improved through exercise or use. The respondent groups of this research were clustered into three (3) as to trainers, clinical instructors and trainees from three (3) caregiver schools and two (2) affiliated hospitals. It utilized the descriptive method with the TESDA adopted survey questionnaire as the instrument. The statistical treatments used were simple percentage, weighted mean and T-test. The findings revealed that the educational qualification and achievements of the trainers and clinical instructors met the prescribed competencies required by TESDA. Hence the Dual Training System (DTS) competency-based curriculum was Fully Delivered with an average weighted mean of 2.41 to the trainee respondent groups. The level of the DTS competency-based curriculum implementation as to basic, common and core competencies had a weighted mean of 2.91 described as Fully Implemented. There is a significant relationship between the trainees' in-bound rating of a weighted mean grade of 88 and DTS performance rating with a weighted mean grade of 90 . There is no significant difference as to the perceptions on the extent of DTS competency-based curriculum implementation among the respondent groups. Thus, it is concluded that the integration of the Dual Training System Competency-Based Curriculum improved the trainees' performance. Thus, the Training Manual which is the output of this research is highly recommended.
\end{abstract}

\section{Subject Areas}

Education 


\section{Keywords}

Health, Social and Community Services, TESDA Dual Training System for Caregiver Schools, Descriptive Method, Cebu City, Philippines

\section{Introduction}

The trifocalization of the management of the Philippine educational system has paved the way for the following changes: formal and non-formal education. This change divides three (3) local agencies that support formal education, the DepEd and CHED, while the non-formal education is spearheaded by the TESDA. The vocational training has been facilitating the following clientele: the bachelor's degrees that are yearning to acquire skills, the out of school youth including the adults, who were not able to avail formal education. It concluded that through the specific need of the different levels/categories of a particular trainee/student they can be well attended to for effective and efficient implementation of their chosen program.

The Technical Education Skills Development Authority (TESDA) and the Dual Training System has been incorporated for almost 38 years since 1980. This dual approach was introduced by the previous President Fidel V. Ramos through its joint project in the Southeast Asian Foundation and the Hanns Seidel Foundation (German Model) [1].

The study of Azmi Bin Amhad, September 2011 stated that "New paradigm of skills training is better known as National Dual Training System (NDTS)". The main problem is that there were complaints from the employers that the competencies of the output of the skills training in Malaysia are of poor quality [2]. Based on the above-mentioned article the researcher agrees his discussions as many of the employers in the Philippines encounter problems of their newly hired employees, such as: skills, knowledge, comprehension and most especially the lack of training from the classroom setting towards the workplace. The learning from in-bound training must be transfer to the real practical area, so that malpractices can be avoided.

According to Norhayati Yahaya, Mohamad Sattar Rasul \& Ruhizan Mohamad Yasin, 2017 Authentic Teaching and Learning is an approach that aims to enhance the trainees' motivation and learning experience by creating Teaching and Learning activities that reflect real-life situations [3]. Agreeably the most effective and efficient way of transferring knowledge and skills to learners is in such a way that interest and open-mindedness in learning techniques and strategies must be integrated.

Likely, Dual Training System as discussed by Seymour Epstein on Cognitive-experiential self-theory (CEST), is a dual-process model of perception which is based on the idea that people operate using two separate systems for information processing: analytical-rational and intuitive-experiential [4]. 
Materially trainees will then be able to apply their training by using suitable resources or books or manuals, state of the art facilities and equipment aligned with their On-The-Job-Training Area.

Thomas Deissinger, 2015 in his article entitled "The German dual vocational education and training system as 'good practice'?” [5]. Explained further that, learning is taken in two venues both structural, institutional and physical. This becomes clear that political lobbying in various government sectors influences the approval of these learning institutions, and establishment, which could hinder technical skills, knowledge and comprehension that are essential to the trainees' success.

The Dual Training System program encourages job matching and career pathing for the trainee/student who choose to finish in caregiving program. Tripartite participation of the institutions, the affiliate links and the labor markets open higher percent of availability of employments for DTS graduates. This assails the application of cognitive, skill-based, and affective theories of learning outcomes (Kurt Kraiger, J. Kevin Ford, and Eduardo Salas) [6].

With the creation of the Technical Education Skills Development Authority (TESDA) in 1994, the demand for reforms in skills training was addressed.

This was the mission of the identified Caregiver Schools in Cebu City. In adherence to the Caregiver Code of Ethics which was "To Promote Health and Prolong Life", the mission is indeed, relevant to the integration of the Technical Education Skills Development Authority (TESDA) Dual Training System geared towards Caregiving for global competitiveness. Hopefully, such integration will provide quality education through its affiliate hospitals specifically, the Cebu City Medical Center (CCMC) and the Sacred Heart Hospital (SHH).

In connection, trainer/clinical instructors' educational requirement will vary according to the competency based curriculum handled namely:

1) Basic and Common Competency (Minor Subjects):

a) Bachelors' Degree Graduate in any business or any related course;

b) Passed the National Certification Exam in Caregiving NC II;

c) Attended the Trainers' Methodology and Assessors' Methodology Course;

d) NTTC Certificate (National TVET Trainers' Certification); and

e) Relevant Training and Seminars Attended.

2) Core Competency (Major Subjects):

a) Graduate in Bachelor of Science in Nursing;

b) Registered Nurse;

c) Passed the NC II Exam in Caregiving;

d) Attended the Trainers' Methodology and Assessors' Methodology Course; and

e) NTTC Certificate.

Furthermore, for the trainees' educational attainment must have the following requirements:

1) High School Graduate;

2) Must be able to speak, read and understand English; 
3) Physically and mentally healthy;

4) Must possess good moral character;

5) At least 18 years of age; and

6) Passed the YP4SC/NCAE/ALS.

With the collaboration of the school or institution and the hospital the aforementioned institutions ensure that the trainees were fully equipped with employability skills, work knowledge, and attitudes at the end of the training. The general and occupational-related theoretical instruction provided by the school or institution was practiced and enhanced through on-the-job training, which was 40 percent of in-bound training, and 60 percent out-bound training or on-the-job training.

The role of the Government through its competitive advantage towards the nations is dependent on the knowledge, skills and entrepreneurial zeal of the workforce and employability policies of the government (Brown, Hesketh and Williams, 2003) [7].

TESDA was mandated to initiate appropriate training programs that would create partnership with the business sectors. The Dual Training System Republic Act No. 7686 was enacted to strengthen manpower education and training in the Philippines and became the instructional delivery system for the Technical Vocational Education Training Program in the country today [8].

As cited by Codoy and Erlinda, 2005 the skill was regarded as the country's principal bargaining power for higher wages [9]. Prosser and Quiggley, 2001 cited that "Training environment was the working environment itself" [10].

The Public Employment Service Office (RA 8759 PESO ACT of 1999) was to task to facilitate community based employment referral and information service which functioned to provide persons with entrepreneurship access to the various livelihood and self employment programs offered by the government and non-government organizations.

The researcher was inspired to make her research in the TESDA DTS Caregiver Training Manual because of her observation and results in the conducted examinations of all the subjects taken during the lectures, demonstrations skills and review of graduates before taking the National Certification Examinations. It was observed that there were voluminous references with different versions and translations used by the trainees which made them confused, experienced severe headache, disoriented, mislead and overwhelmed of medical terms that are difficult to remember. Through this research output it will be very beneficial for the trainees or students to digest medical terminologies and understand in lay-mans term.

When the data was gathered and tables were computed it discloses the problems that were encountered by the trainees in the implementation of the competency-based curriculum and trainers' delivery of the caregiver program. Thus, these minimum requirements would mean the physical set-up, gadgets, equipments, facilities, amenities and the bulk references that were used in their 
in-bound training.

Hence, there was an urgent need to assess The TESDA (Technical Education Skills Development Authority) Dual Training System at the Identified Caregiver Schools, in Cebu City in order to propose an Enhance Caregiver Training Manual.

\section{Methods}

This research utilizes the descriptive method which describes the population's characteristics, perception, attitudes and motivation to understand how they are formed. As defined by Selltiz, et al. [11] the major emphasis was on the discovery of ideas and insights.

Collecting data using this approach was through exploratory and normative surveys. These were: procuring, organizing, analyzing and interpretation of data.

After the data would be gathered, the responses were tallied, collated, tabled and subjected to the statistical computation, namely: simple percentage, weighted mean and T-test.

\section{Results and Discussions}

\subsection{Respondents}

The respondent groups of this study were clustered into three (3) these were: the Asian College of Technology (ACT) or Group A, ABQ International Health Caregiver Program and Consultancy or Group B, and the Southwestern University (SWU) or Group C, Trainers or Clinical Instructors, Trainees and the Affiliate Hospital Personnel (Cebu City Medical Center Hospital and Sacred Heart Hospital). The distribution of the Trainers and or Clinical Instructors was dependent on the institutions type of schedule matrix that was currently used in the program. ACT used the group cycle type (minimum of ten), while ABQ International Health Caregiver Program and Consultancy uses continuous cycle, whereas SWU uses per semester type since they adopted Ladderized Education Program (LEP).

\subsection{Competency Based Training}

Figure 1 illustrates the Flowchart on Competency-Based Training Delivery of how trainees were being screened in preparation to the classroom setting discussion. This brought to mind the Trait Theory, an approach primarily interested in the measurement of traits, which can be defined as habitual patterns of behavior, thought and emotion. According to this perspective, traits are relatively stable over time, differ across individuals (e.g. some people are outgoing whereas others are shy), that influence behavior (Psychologist Gordon Allport (July 9, 2018), Pages 1028-1036 [12].

Moreover, the diagram below explains the process or steps as follows: First, the students or trainees enter a program they are being oriented regarding the program rules and regulation, further clarifies the trainers and trainees roles and 


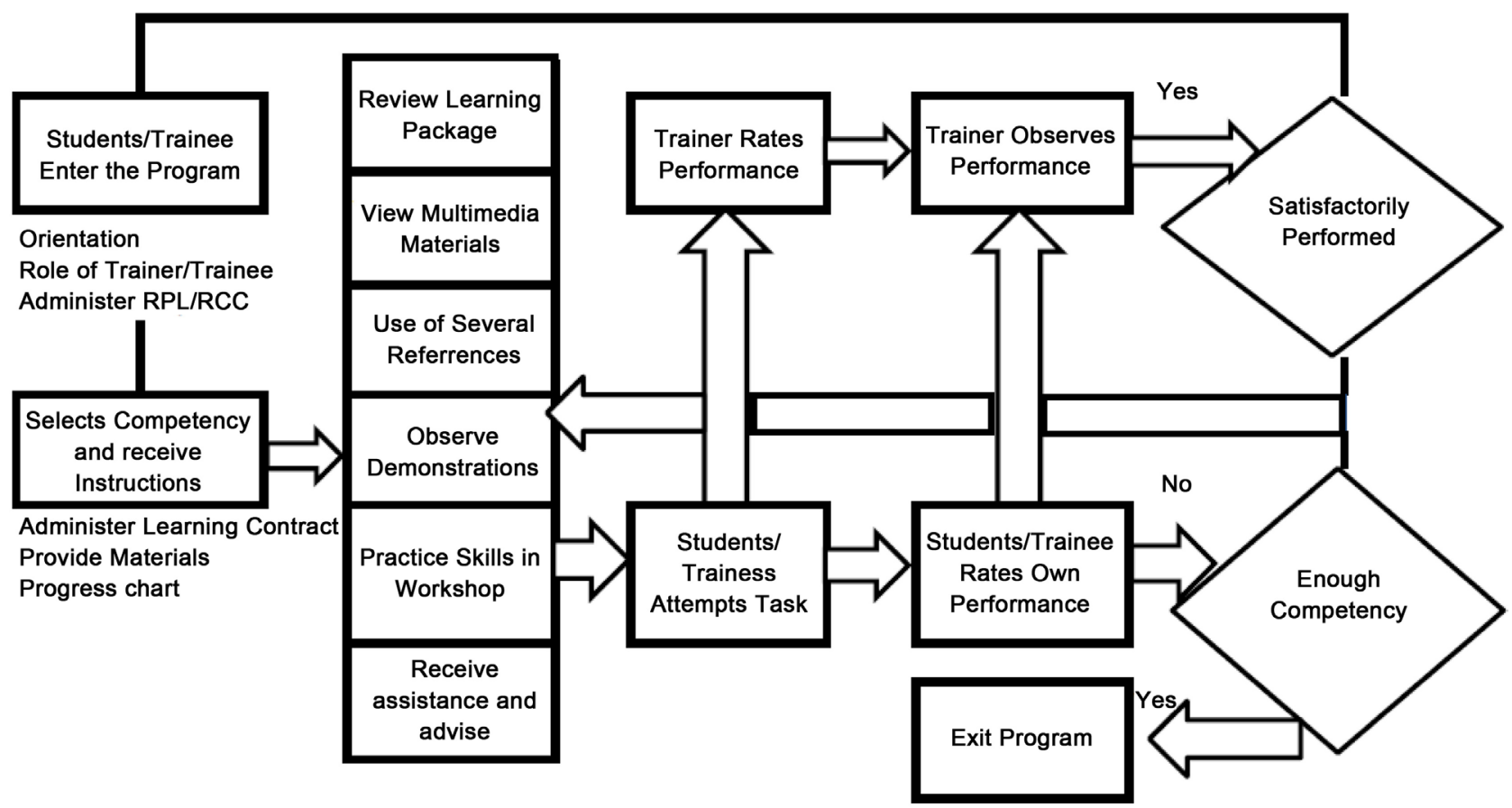

Figure 1. Flowchart on competency based training delivery.

if the prospect trainees have related job experiences they were administered with Recognition to Prior Learning also known as RPL or Recognition to Current Competencies also known as RCC. Second, the successful entrant or enrollee will now be administered with learning contract or enrolment form, voluminous learning materials, and emphasizing the importance of the progress chart which is used to monitor the trainees level of competency recorded in the Trainees' Record Book. Third, the Trainees will enter the program such as; Review Learning Package, View Multimedia Materials, Use Several References Observe Demonstrations, Practice Skills in Workshops and Receive assistance and advice to continue or review the process of the program until such time that the trainee will completely exit the program with National Certification issued by Technical Education Skills Development Authority.

\subsection{Table}

The data in Table 1 shows how the respondents are being sampled. Column 1 was divided into two (2) groups, the first group were the schools in Cebu City they are: ACT, ABQ International Health Caregiver Program and Consultancy, and SWU. The second group was the affiliated hospitals; CCMC and SHH where the trainees were being deployed for their On-The-Job-Training. The second column explains the total number of trainers' or clinical instructors' percentage distribution.

Table 2 presents the significant relationship between trainees in-bound rating and DTS performance. This examines the relationship of the in-bound rating delivered by the trainers' and implemented by the trainees through the DTS 
Table 1. Distribution of the respondents.

\begin{tabular}{cccccc}
\hline \multirow{2}{*}{$\begin{array}{c}\text { A. Caregiver } \\
\text { Schools }\end{array}$} & \multicolumn{2}{c}{$\begin{array}{c}\text { Trainers } \\
\text { /CI }\end{array}$} & \multicolumn{2}{c}{ Trainees } & Percentage \\
\cline { 2 - 6 } & F & $\%$ & Enrolled & $50 \%$ & \\
\hline ACT & 4 & 50.00 & 84 & 42.00 & 33.00 \\
ABQ & 2 & 25.00 & 80 & 40.00 & 31.00 \\
SWU & 2 & 25.00 & 92 & 46.00 & 36.00 \\
Total & 8 & 100.00 & 256 & 128 & 100.00 \\
\hline B. Affiliate & & Trainers & & Trainees & \\
Hospitals & & $/$ CI & & & Percentage \\
\hline CCMC & 3 & 50.00 & 64 & 50.00 & 50.00 \\
SHH & 3 & 50.00 & 64 & 50.00 & 50.00 \\
Total & 6 & 100.00 & 128 & 100.00 & 100.00 \\
\hline
\end{tabular}

Table 2. Significant relationship between trainees in-bound rating and OJT performance.

\begin{tabular}{|c|c|c|c|c|}
\hline Areas & df & $\begin{array}{l}\text { Critical } \\
\text { Value }\end{array}$ & Decision & Interpretation \\
\hline A & 22 & $5.12>1.78$ & $\begin{array}{l}\text { Do not } \\
\text { accept }\end{array}$ & Significant \\
\hline B & 22 & $3.88>1.78$ & $\begin{array}{l}\text { Do not } \\
\text { accept }\end{array}$ & Significant \\
\hline $\mathrm{C}$ & 22 & $7.10>1.78$ & $\begin{array}{l}\text { Do not } \\
\text { accept }\end{array}$ & Significant \\
\hline
\end{tabular}

performance rating in the affiliate hospitals (CCMC and $\mathrm{SHH})$.

Furthermore, the table above tested whether there is a significant relationship between trainees' in-bound rating and DTS performance rating in A, which obtained a test value of 5.12 which was greater than the critical value of 1.78 which means do not accept the hypothesis. The findings implied that there is significant relationship that existed. It implied that training has a significant impact to the performance.

Moreover, whether there is a significant relationship between trainees in-bound rating and DTS performance rating in B, have obtained a t-test value of 1.78 which means do not accept the hypothesis. The findings implied that there is significant relationship that existed. I implied that training has beneficial effect to the performance.

Lastly, whether there is significant relationship between trainees' in-bound rating and DTS performance rating in C, it obtained a t-test value of 7.10. This means do not accept the hypothesis. The findings revealed that there is a significant relationship that existed. It implied that training has beneficial effect to the trainees' performance. 
This concluded that instructional design must be learned and should be organized from simple to complex order, while providing a meaningful context in which it has subsequent ideas which can be integrated (Charles Reighluth, 2010 "Elaboration Theory") [13]. This would help select and sequence the learning content in a way that it will optimize attainment of learning goals.

Table 3 illustrates the perceptions of the trainers and trainees on the extent of DTS competency based curriculum implementation; obtained a t-test value of 0.86 which is lesser than the critical value of 1.98 which means the acceptance of the hypothesis. The findings implied that there is no significant difference on the responses of the trainers and trainees as to the extent of DTS competency-based curriculum implementation. Both were perceived that the DTS competency-based curriculum is important in promoting the welfare of the caregiving schools in meeting the expectations of the trainees or students. This would help select and sequence the learning content in a way that will optimize attainment of learning goals.

\subsection{Statistical Treatment}

$$
t=\frac{\left(x_{1}-x_{2}\right)}{\sqrt{\frac{\left(S_{1}\right)^{2}}{n_{1}}+\frac{\left(S_{2}\right)^{2}}{n_{2}}}}
$$

Two Sampled T-test was applied to determine whether there was a significant mean difference between the perception of respondent groups as to the competencies delivered by trainers and acquired by trainees. The data was interpreted using the following non-parametric scale:

\begin{tabular}{cc}
\hline \multicolumn{2}{c}{ Trainers Delivery of the Curriculum Based Competencies } \\
\hline Scale & Category \\
\hline $2.34-3.00$ & Fully Delivered (FD) \\
$1.67-2.33$ & Delivered (D) \\
$1.00-1.66$ & Least Delivered (LD) \\
\hline Trainees Implementation of the Curriculum Based Competencies & Category \\
\hline Scale & Fully Implemented (FI) \\
\hline $2.34-3.00$ & Implemented (I) \\
$1.67-2.33$ & Least Implemented (LI) \\
\hline $1.00-1.66$ &
\end{tabular}

Table 3. Significant difference between the perceptions of trainers and trainees on the extent of DTS competency-based curriculum implementation.

\begin{tabular}{cccccc}
\hline Variables & df & t-test value & Critical Value & Decision & Interpretation \\
\hline $\begin{array}{c}\text { Trainees and } \\
\text { Trainees }\end{array}$ & 136 & & $0.86<1.98$ & Accept & $\begin{array}{c}\text { Not } \\
\text { Significant }\end{array}$ \\
\hline
\end{tabular}


The findings revealed that the educational qualification and achievements of the trainers and clinical instructors met the prescribed competencies required by TESDA. Hence the Dual Training System (DTS) competency-based curriculum was Fully Delivered with an average weighted mean of 2.41 to the trainee respondent groups. The level of the DTS competency-based curriculum implementation as to basic, common and core competencies had a weighted mean of 2.91 described as Fully Implemented. There is a significant relationship between the trainees' in-bound rating of a weighted mean grade of 88 and DTS performance rating with a weighted mean grade of 90 . There is no significant difference as to the perceptions on the extent of DTS competency-based curriculum implementation among the respondent groups.

There were implausible effects encountered by the trainee respondents during the delivery of the DTS competency-based curriculum. The research identified six (6) serious problems according to the following; difficulty in relating to in-bound training discussions, difficulty in dealing with actual demonstrations and situations, difficulty in absorbing/digesting medical terminologies and applications in a shorter span of time, difficulty in doing cardio-pulmonary resuscitation, difficulty in doing basic first aid, and voluminous references with complicated discussions. Trainer respondents identified serious problems in imparting knowledge to the trainees, namely; lack of up-to-date state of the art technology or equipment, lack of updated books and resource materials, lack of seminars and trainings which will relate to actual situations, and no security of tenure.

This implicates that the relationship of the in-bound rating and DTS performance were fully delivered by the trainers and fully implemented by the trainees during their on-the-job training in their respective hospital.

\section{Conclusions}

The training in caregiving conducted in the University, Colleges, and Learning Centers through its adaptation on the Ladderized Education Program confused and perturbed many trainees or students due to the voluminous sources referred by the trainers. Even though there are several versions that might introduce the arts in caregiving, yet there must be a specific and consolidated instructional material that identifies the subjects covered from the trainers' training guidelines entrenched by the Technical Education Skills Development Authority.

Based on the findings of the research, it is recommended that the researchers' study on the skills, theory and practices of the present caregiver training must be produced. However, propound intervention must be provided and the following recommendation should be given consideration which is to create and enhance caregiver training manual.

\section{Conflicts of Interest}

The author declares no conflicts of interest regarding the publication of this paper. 


\section{References}

[1] Mapula (2006) Competencies Delivered by Trainers and Acquired by Trainers of Cebu Center for Skills Development \& Training.

[2] Ekpenyong and Nwabuisi (2001) Revisiting the Theories of Vocational Education. Module, 2, 30-41.

[3] TESDA (2010) Training Regulation.

[4] TESDA (2010) Competency Based Curriculum Exemplar NC II.

[5] Oxford Dictionary (2002).

[6] Condevillamar (2008) Inputs for Management Plan.

[7] TESDA VII Cebu Trainer's Training Methodology.

[8] TESDA Planning Office (2010) TVET. Glossary of Terms. 4th Edition.

[9] Philippine National Red Cross (2010).

[10] Banach, Banach and Cassidy (1996) The ABC Complete Book of School Marketing. Ray Township.

[11] Brohhead, C.W. (1991) Image 2000, January 1991: A Vision for Vocational Education. Vocational Journal, 66, 22-25.

[12] Buzzell, C.H. (1987) Let Our Image Reflect Our Pride. Vocational Education Journal, 62, 10.

[13] Kincheloe, J.L. (1995) Toil and Trouble: Good Work, Smart Workers, and the Integration of Academic and Vocational Education. Peter Lang Publishing, New York. 